Mal J Nutr 26(3): 501-524, 2020

\title{
REVIEW
}

\section{A review of national plans of action for nutrition in Southeast Asian countries}

\author{
Tee E Siong ${ }^{1,2^{*}}$, Rodolfo F Florentino ${ }^{1,3}$, Hardinsyah ${ }^{1,4}$, Ismail Mohd Noor ${ }^{1,2}$, \\ Lwin Mar Hlaing ${ }^{5}$, Saipin Chotivichien ${ }^{6}$ \& Le Thi Hop ${ }^{1,7}$
}

${ }^{1}$ SEA-PHN Network; ${ }^{2}$ Nutrition Society of Malaysia; ${ }^{3}$ Nutrition Foundation of the Philippines, Inc; ${ }^{4}$ Food and Nutrition Society of Indonesia; ${ }^{\mathbf{5}}$ National Nutrition Centre, Ministry of Health and Sports, Myanmar; ${ }^{6}$ Bureau of Nutrition, Ministry of Public Health, Thailand; ${ }^{7}$ Vietnam Nutrition Association, Vietnam

\begin{abstract}
This review describes national plans of action for nutrition (NPANs) in six Southeast Asia countries (Indonesia, Malaysia, Myanmar, Philippines, Thailand and Vietnam) in order to provide an understanding of the approach and framework undertaken by these countries in the formulation and implementation of NPANs, as well as the similarities and differences in various NPAN components. The six countries recognised the persistent undernutrition and escalating rates of obesity and other diet-related chronic diseases as the key drivers for nutrition action plan implementation. The prioritisation of nutrition interventions outlined in these NPANs are based on respective country context and needs. Although differing in strategies and targets set, these countries show similarities in several components including objectives, stakeholder involvement, nutritional issues to be addressed, implementation, monitoring and evaluation mechanism, programme/ activities identified and challenges in implementing NPANs. Countries have recognised that effective implementation, monitoring and evaluation are essential to successfully address both extremes of the challenging nutrition situation. Several important similarities in the NPANs studied suggest that closer collaboration among countries and stakeholders on NPANs would be beneficial. Opportunities should be created for periodic exchanges to enable sharing of experiences in the development and implementation of NPANs among the countries. Recommendations and conclusions drawn from this review could serve as useful reference for nutrition policy and planning in the future.
\end{abstract}

Keywords: National plan of action for nutrition, Southeast Asia, nutrition intervention programmes, implementation strategies, monitoring and evaluation

\section{INTRODUCTION}

Countries in Southeast Asia (SEA) region which had, in the past, carried a high burden of child undernutrition has experienced a shift of nutrition scene in which most countries in the region are facing a double burden of malnutrition. This is characterised by persistent undernutrition including stunting, wasting, micronutrient deficiencies and

\footnotetext{
*Corresponding author: Dr Tee E Siong

Chairman, Southeast Asia Public Health Nutrition (SEA-PHN) Network

Email: president@nutriweb.org.my

doi: https://doi.org/10.31246/mjn-review-26-3
} 
coexisting overweight and obesity across the life cycle. Concern about diet-related chronic non-communicable diseases (NCDs) has also grown as they have been found to be responsible for major and growing proportion of the health burden (Shrimpton \& Rokx, 2012; WHO, 2016).

The health systems of the region that were previously geared towards fighting widespread undernutrition, will now need to curb the rising rates of overweight and obesity in order to reduce NCDs. The focus of countries' food policies and national plan of action for nutrition (NPAN) have shifted to address the changes in nutrition scene. Well-established nutrition policies and plans are important tools in guiding the nations in dealing with nutritional issues as well as providing a framework for coordinated implementation of nutrition intervention activities by the government and cross-sectoral nutrition stakeholders in the country. Moreover, the World Health Organization (WHO) has emphasised that unless food and nutrition plans are implemented, unsafe food and poor nutrition will be responsible for an increased economic burden from food-related morbidity and premature mortality (WHO, 2000).

Many countries, including countries in the SEA region have reviewed their own NPAN following the Rome Declaration on Nutrition and the Framework for Action, arising from The Second International Conference on Nutrition (ICN2) in 2014. The present paper analysed NPANs in six SEA countries (Indonesia, Malaysia, Myanmar, Philippines, Thailand and Vietnam) in order to provide an understanding of the approach and framework undertaken by countries to formulate NPANs; stakeholder involvement, main nutritional problems targeted; strategies and programmes identified; and the implementation and monitoring mechanisms. Through this review, useful information on aspects of
NPAN will become available for sharing with other countries which are developing or reviewing national nutrition action plans. Besides, conclusions drawn from this review could also serve as useful reference for nutrition policy and planning in the future.

\section{METHOD}

This review of NPANs in six SEA countries is based on the SEA-PHN Network's monograph on NPANs in SEA countries that was first published in 2018 (Tee et al, 2018). The intention of this review article is to provide a concise version of the 88-page monograph in a journal article that can have a wider reach to potential users. More details for the action plans that are beyond this review can be obtained from the monograph. Upon checking with the relevant authorities for any updated versions of these action plans, it was found that except for Myanmar and Thailand, all the documents cited in the monograph are still in use in the countries. The updated NPAN in Myanmar and Thailand are used in this journal review.

The NPANs used for this review are namely: National Food and Nutrition Action Plan (NFNAP) (Rencana Aksi Nasional Pangan Dan Gizi, RANPG) 20152019 (BAPPENAS Indonesia, 2015) (this plan is phasing out in 2019 and a new one is in preparation); National Plan of Action for Nutrition of Malaysia (NPANM) III 2016-2025 (NCCFN Malaysia, 2016); Myanmar's Multi-sectoral National Plan of Action on Nutrition (MS-NPAN) 2018/19 - 2022/23 (NNC Myanmar, 2018); Philippine Plan of Action for Nutrition (PPAN) 2017-2022 Executive Summary (NNC Philippines, 2017); Vietnam National Plan of Action for Nutrition to 2020 (MOH Vietnam, 2018) and Thailand's 5-Year National Plan of Action for Nutrition 20192023 (MOPH Thailand, 2019). The 
key components of the NPANs were analysed and discussed. This includes formulation of the NPANs, stakeholder involvement, goal and objectives of different NPANs, nutritional issues addressed by the NPANs, strategies, programmes and activities identified for implementation, institutional framework for implementation, monitoring and evaluation approaches, and budget allocation. The challenges in implementing previous NPANs are also discussed.

\section{RESULTS \& DISCUSSION}

\section{Background of development of NPANs}

Most of the NPANs in the six countries were first published in late 1990s or early 2000s, responding to the call of the first ICN on concerted effort to reduce starvation and all forms of malnutrition. The Philippines and Thailand formulated their first NPAN as early as 1970s. All countries had recognised the persistent undernutrition and parallel rise of the rates of obesity and other diet-related chronic diseases as the key drivers for nutrition action plan implementation. The NPANs in these countries have been developed by nutrition and health authorities of the respective countries, usually with extensive consultations and inputs from food and nutrition experts in the country, technical working groups, relevant stakeholders as well as international organisations such as Food and Agricultural Organization (FAO), WHO and the World Bank. Most of the plans were designed based on scientific evidence reviews, the experiences and lessons learnt from the past implementations, as well as detailed analyses of the nutrition situation in the respective country. These documents serve similar role of acting as framework for action and blueprint/reference documents by different stakeholders to address nutrition challenges in the country. Table 1 summarises the background of the NPANs in the six SEA countries and the stakeholders involved in the implementation.

\section{Stakeholders involvement in the implementation of the action plans}

The importance of multidisciplinary approach has been acknowledged by all the NPANs in which collective responsibility and involvement of all stakeholders in the development and implementation of the action plans are stressed and promoted.

The stakeholders pulled together by most of the countries are primarily the governmental organisations (Table 1). Other typical stakeholders include non-government organisations (NGOs), universities, professional bodies, socialpolitical organisations and associations, and international organisations. All countries in this review, except Malaysia, are Scaling Up Nutrition (SUN) Movement member countries. Myanmar provides elaboration of the specific roles of each stakeholder identified.

Most NPANs also acknowledge the importance of involving media and private sector, particularly food-related industries. Food industries in Malaysia have been encouraged to play a major role in producing healthier food and beverage products at affordable prices through reformulation and innovation. In Vietnam, private sector is encouraged to increase production of specialised nutrition products to be used specifically among poor and disadvantaged groups.

\section{Goal and objectives of different NPANs}

The six NPANs reviewed present different goals with majority give emphasis to hunger eradication, prevention/ reduction of all forms of malnutrition, promotion of food and nutrition security and achievement of nutritional well- 


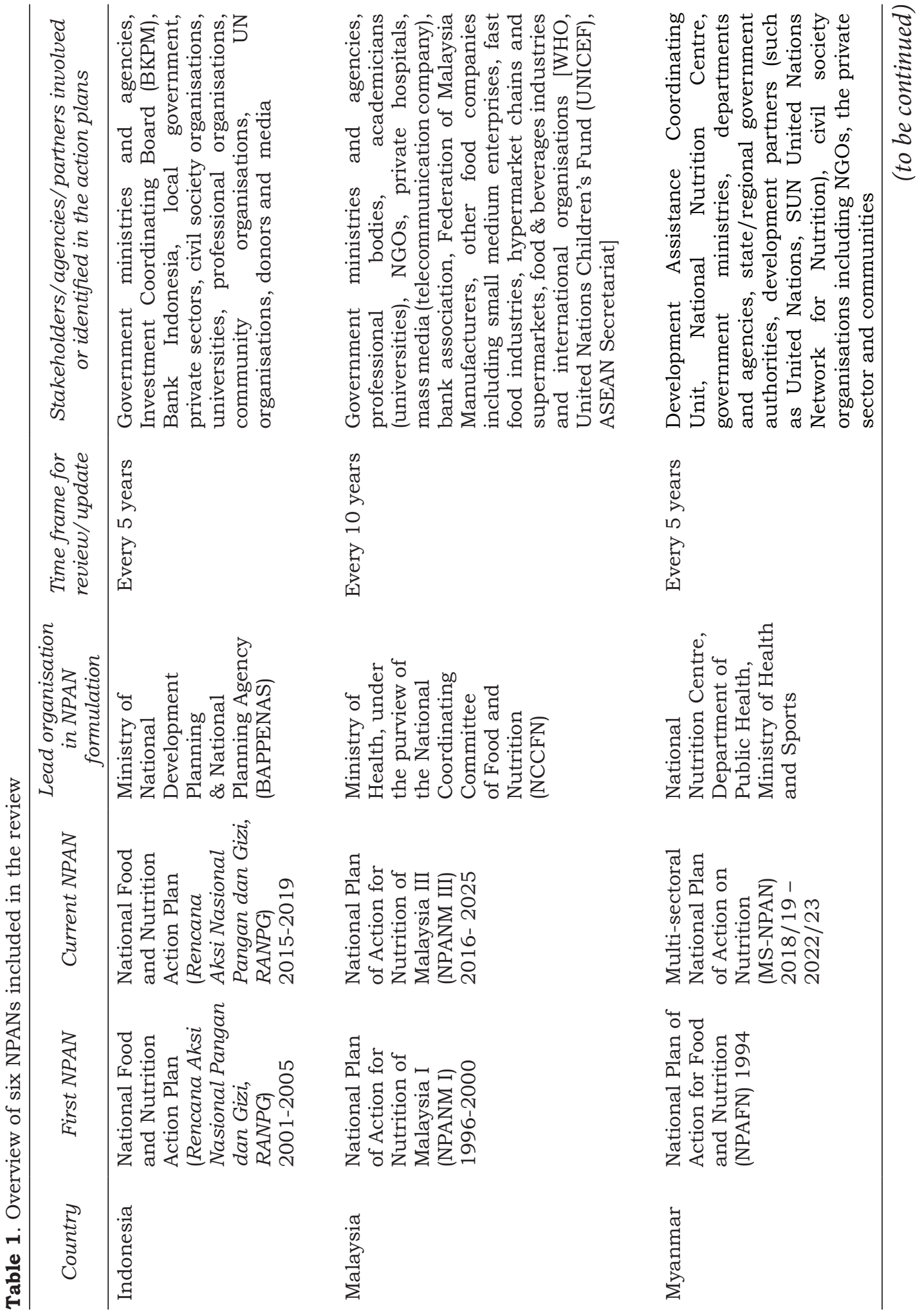




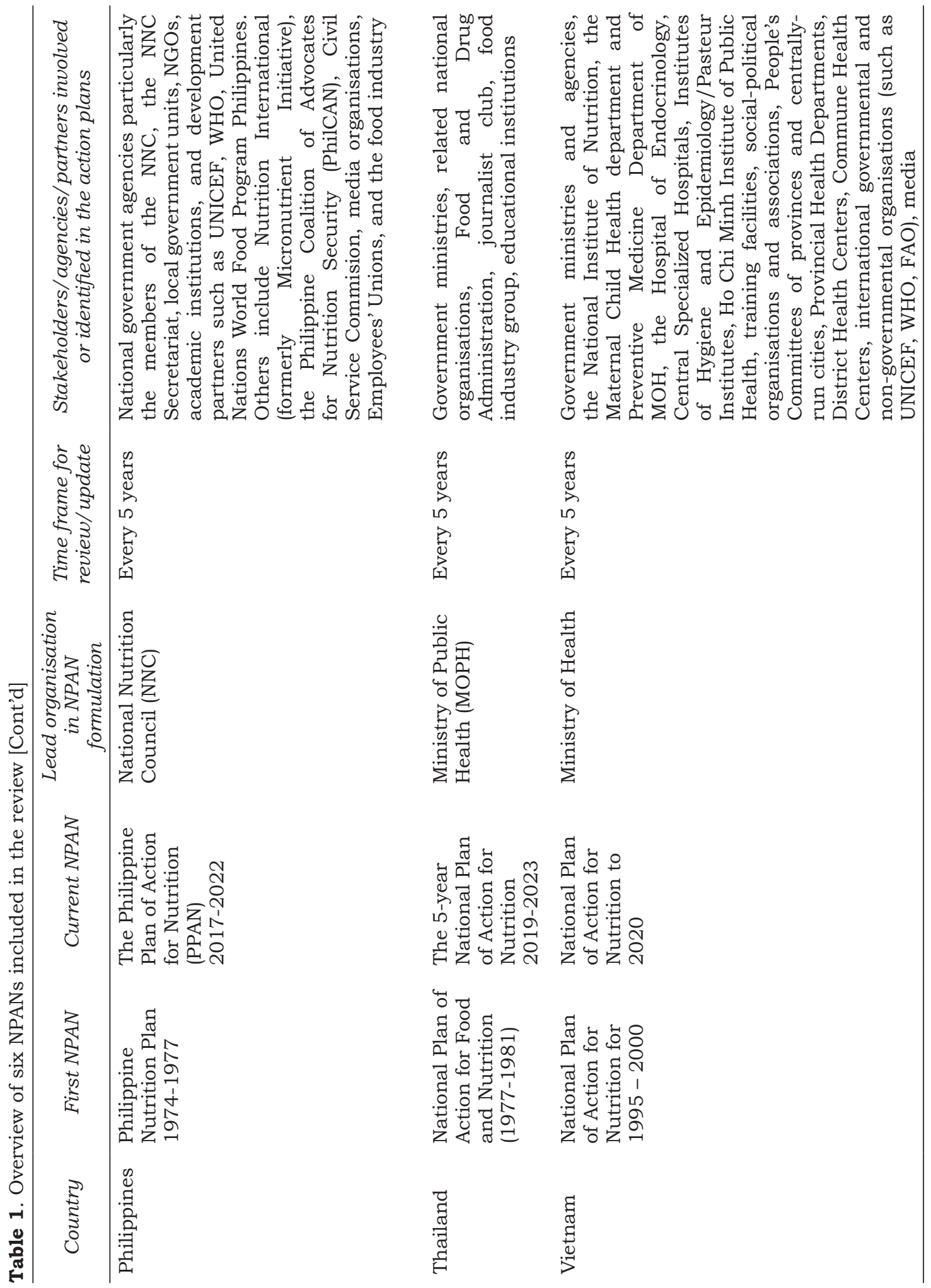


being. Slightly different from other NPANs, Thailand's action plan is developed in line with the food education strategy in the country's $2^{\text {nd }}$ Strategic Framework for Food Management in Thailand 2018-2037, giving emphasis to creating desirable behaviour in healthy food consumption. Most NPANs have similar objectives with emphasis on improving nutritional status of the population, preventing and/or reducing undernutrition and diet-related NCDs, and improving food and/or nutrition security. It is noteworthy that the goal and objectives outlined in these countries' NPAN are consistent with internationally agreed recommendations such as the Rome Declaration and the Framework for Action on Nutrition, and will contribute to the Sustainable Development Goals (SDGs) 2030 of the UN, particularly SDG 2 (end hunger, achieve food security and improved nutrition and promote sustainable agriculture), SDG 3 (good health and well-being), as well as the results of the World Health Assembly for 2025.

\section{Nutrition issues to be addressed in action plans}

As most countries in the region face similar situation of double burden of malnutrition, it is not surprising that the different NPANs show similarities in the nutrition situation and issues identified to be addressed (Table 2).

Some of the common priority nutritional issues identified include low exclusive breastfeeding rate; high prevalence of stunting, underweight and wasting amongst children under 5 years of age; increased prevalence of obesity and nutrition-related NCDs; micronutrient deficiencies; low vegetables and fruits intake; and low physical activity levels among the population.

Specific nutritional issues that are considered important to be addressed by respective countries are also identified, for example the problem of high salt, high fat foods consumptions, and protein consumption that are not meeting requirement in Indonesia; prevalence of low birth weight and teenage pregnancy in Myanmar; hunger in Philippines; and lower physical status and stature of the population in Vietnam.

\section{Framework for NPANs}

All NPANs in this study, except Vietnam, had developed a framework for the respective nutrition action plan. All of these frameworks developed are presented in pictorial format (Figures 1-5). These frameworks show one commonality wherein all of them summarise the goal, priorities and strategies identified for the action plan.

\section{Strategies, food and nutrition programmes and activities}

In alleviating the nutrition issues of the country, the NPANs in this review has prioritised the nutritionally vulnerable groups i.e. infants and young children, pregnant and lactating women.

\section{Key strategies in NPANs}

The overarching strategy of Malaysia is their foundation strategy which emphasises the responsibilities of all relevant agencies. Nutrition objectives, considerations and components are to be incorporated into national development policies and action plans in other relevant ministries and agencies, with the support of a wide range of enabling and facilitating strategies. In Myanmar, the action plan's key strategy is to strengthen multi-sectoral coordination in nutrition and deliver a package of essential nutrition-specific and nutrition-sensitive services/ interventions with the overall goal to reduce all forms of malnutrition among mothers, children and adolescent girls. The interventions in each state/region prioritise the most important factors 


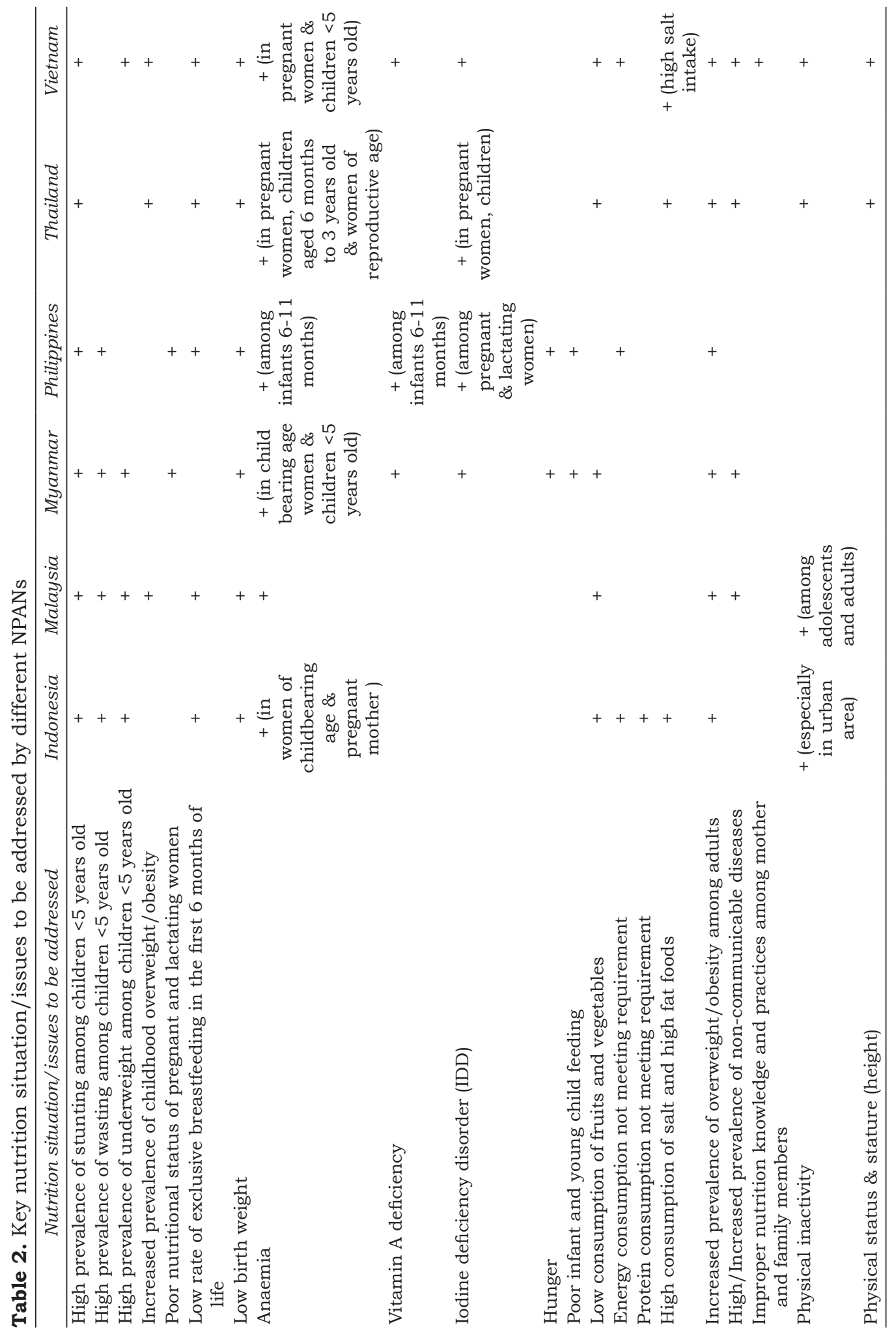




\section{PERBAIKAN KUALITAS SUMBER DAYA MANUSIA}

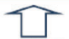

\begin{tabular}{|c|c|c|}
\hline & Manfaat pada Siklus Kehidupan & \\
\hline $\begin{array}{l}\text { Kesakitan/kematian } \\
\text { bayi dan anak }\end{array}$ & 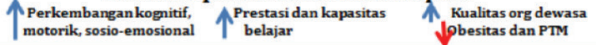 & $\uparrow_{\text {Produktivitas }}^{\text {Kapasitas kerja }}$ \\
\hline
\end{tabular}

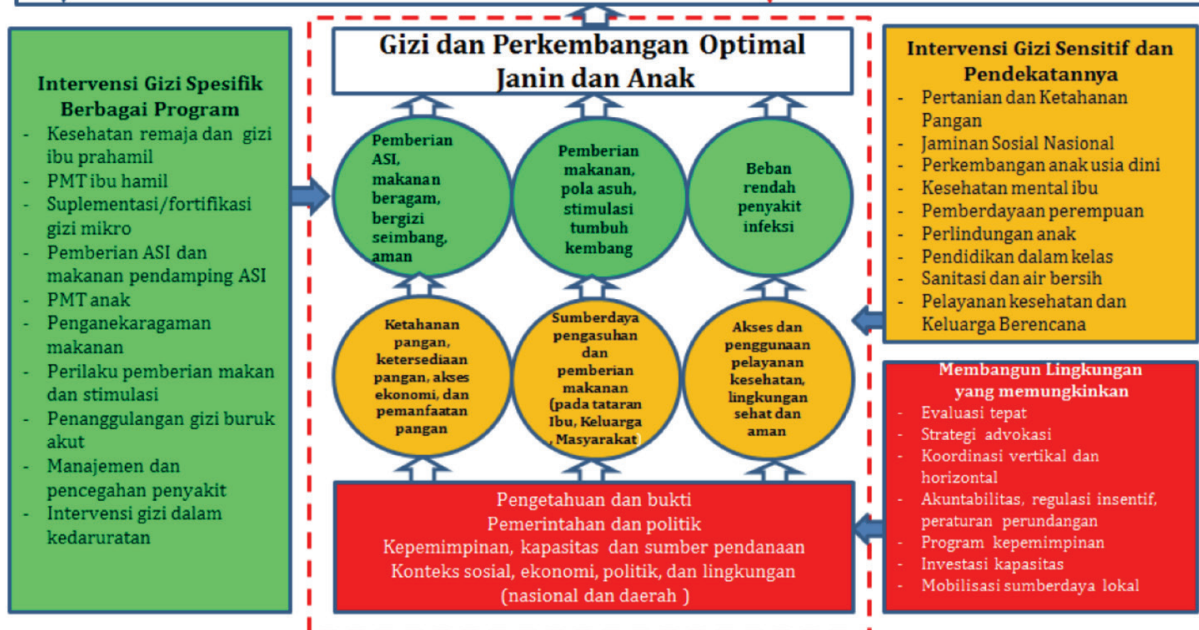

Figure 1. Framework of Indonesia National Food and Nutrition Action Plan (2015-2019)

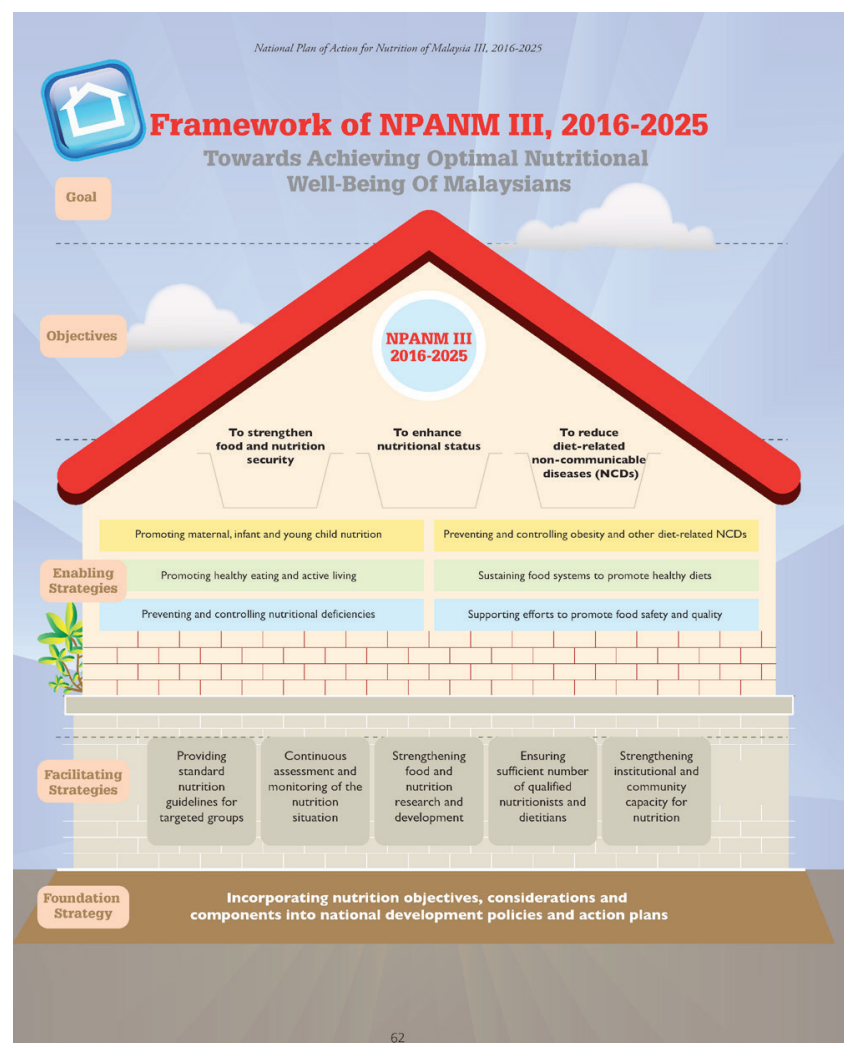

Figure 2. Framework of National Plan of Action for Nutrition III, Malaysia (2016-2025) 


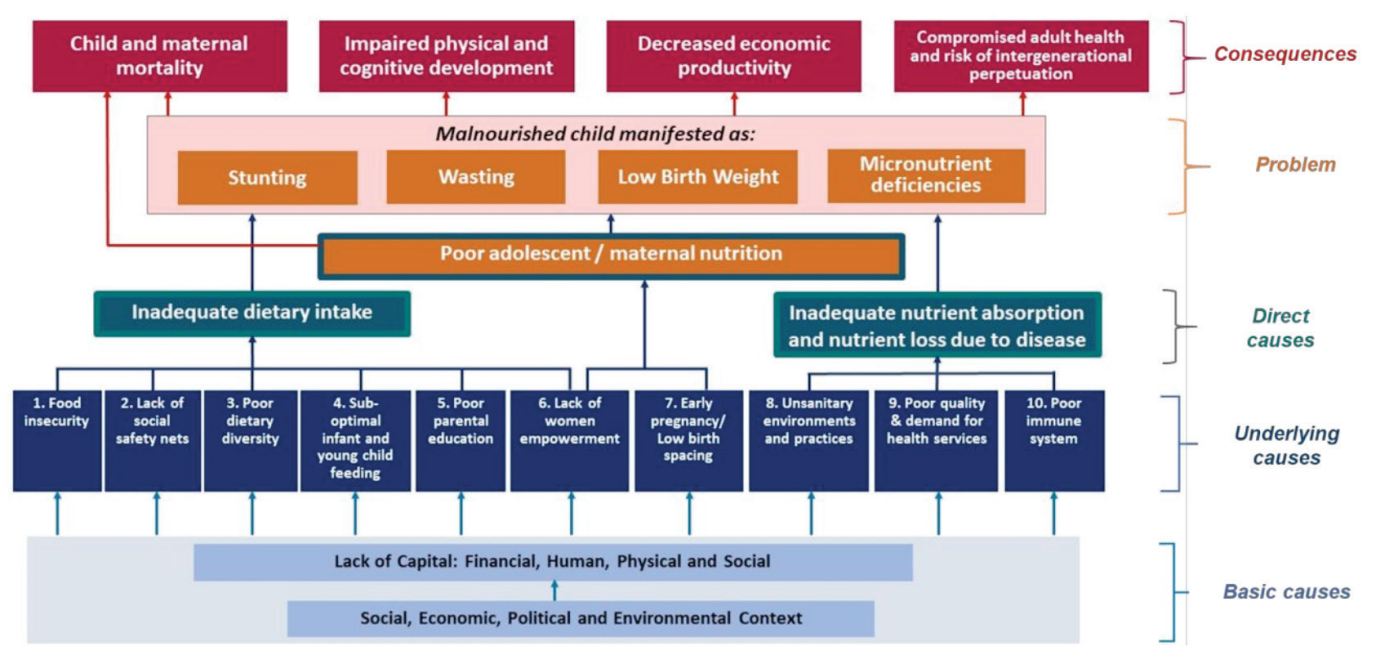

Figure 3. Conceptual Framework of the Multi-sectoral National Plan of Action on Nutrition, Myanmar

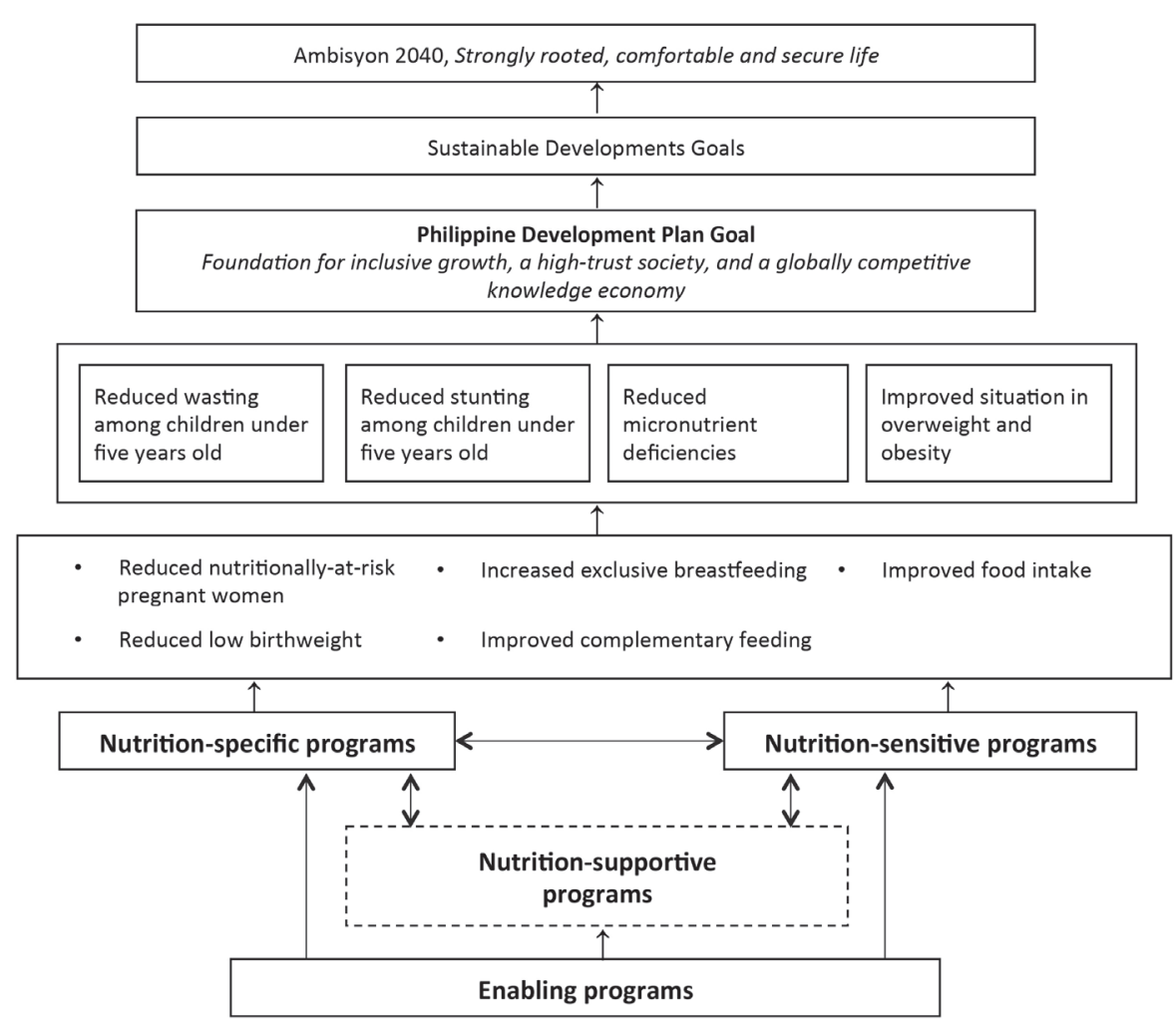

Figure 4. Framework of Philippines Plan of Action for Nutrition (2017-2022) 


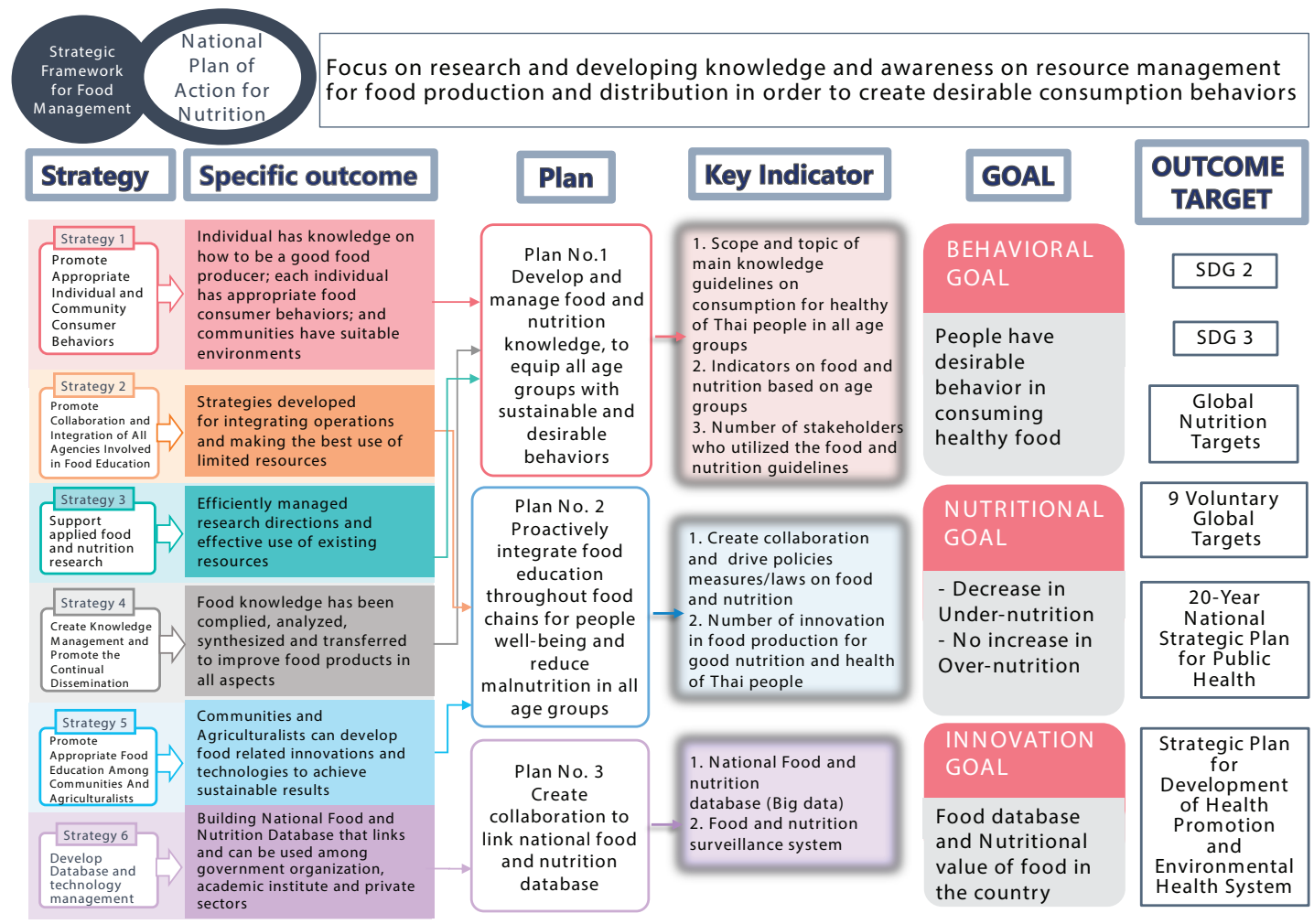

Figure 5. Framework of National Plan of Action for Nutrition, Thailand (2019-2023)

causing poor nutrition as well as interventions that are most responsive to effective operationalisation and scaleup to achieve high coverage and impact. Philippines' strategies focus on the First 1000 Days of Life, complementation of nutrition-specific and nutrition-sensitive programmes, intensified mobilisation of local government units, reaching geographically isolated and disadvantage areas, and complementation of actions of national and local government units.

Community nutrition improvement, increase in food accessibility, food safety enhancement and food and nutrition institutional strengthening are among the important pillars of strategies undertaken by Indonesia in its action plan. Thailand's NPAN strategies focus on the integration of food education throughout the food chains, through the process of promoting, developing and teaching to improve eating behavior thus achieving the goals of improved nutritional status. The three identified focus areas in Thailand's NPAN include develop and manage knowledge about food and nutrition to equip all groups of people with sustainable and proper behaviours; proactively integrate food education in all food chains; and create collaboration to link national food and nutrition database. Vietnam takes different approaches in its NPAN strategies in which the country focuses on legislative, advocacy and communication, technical, science, and international cooperation approaches. 
Food and nutrition programmes \& activities identified

Though the strategies proposed are different among countries, the programmes and activities identified by these NPANs are to some extent, similar (especially among the countries participating in SUN Movement). These can be generally divided into nutrition-specific and nutrition sensitive programmes/activities.

Multi-sectoral approach is utilised by most countries in the programme implementation, where several agencies are involved in one programme or activities with a lead agency identified for every activity. Most programmes identified are in response to the nutrition issues identified by respective country, are relevant to the priority gaps identified in the review, locally appropriate, and adopted after considering the past experiences in implementation capacity in order to achieve the intended nutrition impact. Table 3 provides an overview of common nutrition programmes and activities by these action plans.

Different from other countries, majority of the projects identified in Thailand's NPAN focus on development of knowledge, techniques, indicators and tools for behaviour modification and consumption changes; development of food education system (formal and nonformal) and national database on food and nutrition in which the nutrition data system will also be used for food and nutrition surveillance system.

\section{a. Nutrition promotion during the first} 1000 days of life

The importance of good nutrition during the first 1000 days of life is recognised by most NPANs in addressing the persistent undernutrition problems. Exclusive breastfeeding is being promoted by all countries and that Vietnam is taking the initiative to develop regulations on the operation of the breast milk bank.
Other common activities undertaken to promote mother and children nutrition include education on complementary feeding; nutrition intervention for teenage girls, pregnant women and mothers; children nutritional status monitoring; supplementary provision of nutritional products for mothers/children at risk for poor nutrition, antenatal and post-natal care, baby friendly hospital initiative and control of the marketing of infant foods.

\section{b. Addressing nutritional needs/ nutrients deficiencies}

Dietary supplementation, micronutrient supplementation and food fortification are among the common activities outlined by these NPANs to safeguard the health and population's nutritional needs. Most countries implement dietary supplementation programmes for different target groups, particularly the vulnerable groups of infants, children and mothers. School feeding or school milk programme exist in all six countries (Table 3). Iron and folic acid supplementation and iodisation of salt are implemented by all six countries. Multiple micronutrients supplementation for high-risk groups is common in the NPANs of these countries. NPANs of these countries also respectively identified several staple foods such as rice, flour and oil for nutrients fortification (Table 3).

\section{c. Food and nutrition security enhancement}

Most NPANs underscore the need to increase/diversify local food production and utilisation. Several countries have price control system in place. Indonesia, Malaysia, Myanmar and Thailand integrate nutrition component/foodbased nutrition education into the planning of food supply, agricultural and production. The community healthy food production project in Thailand 


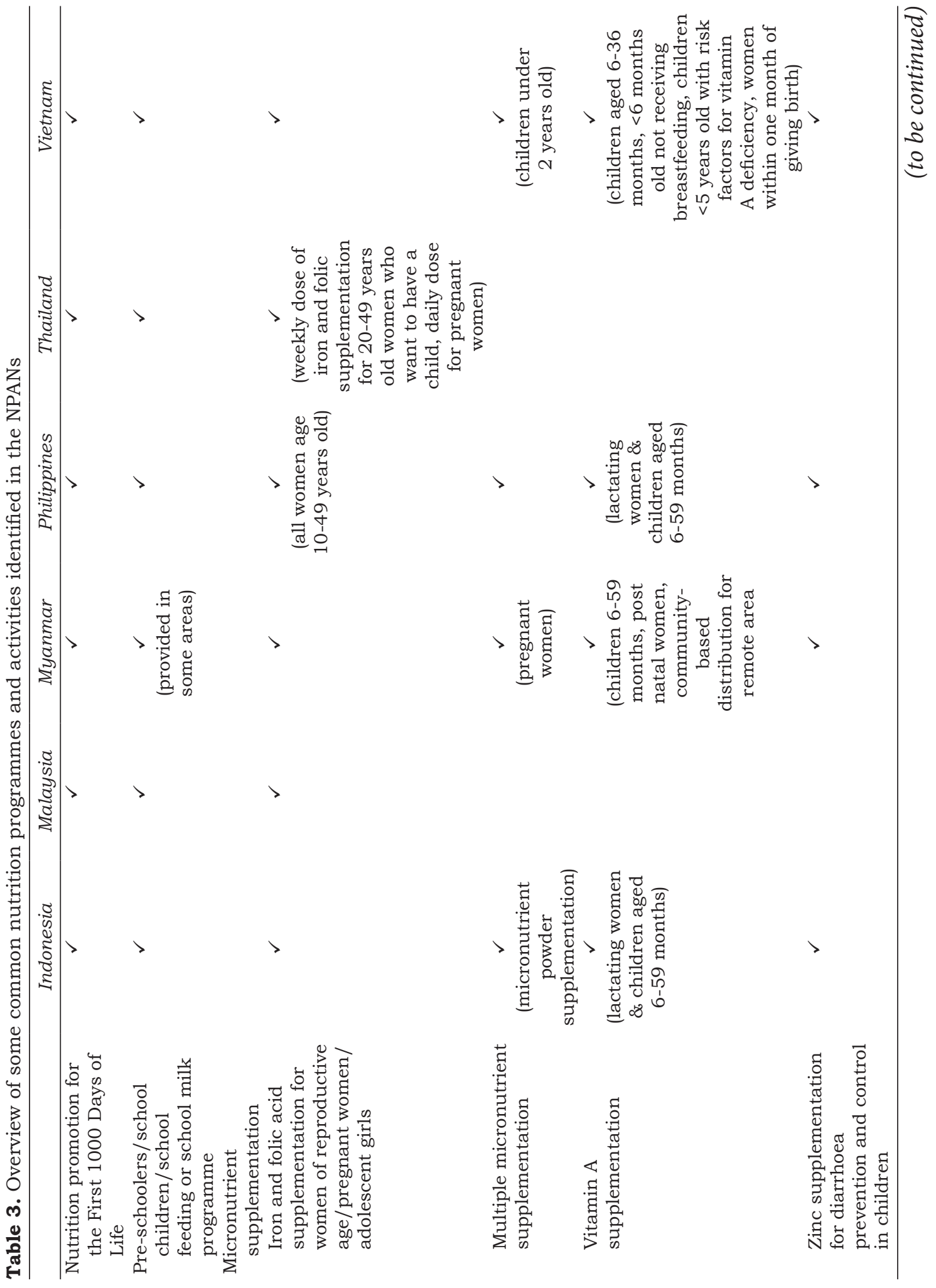




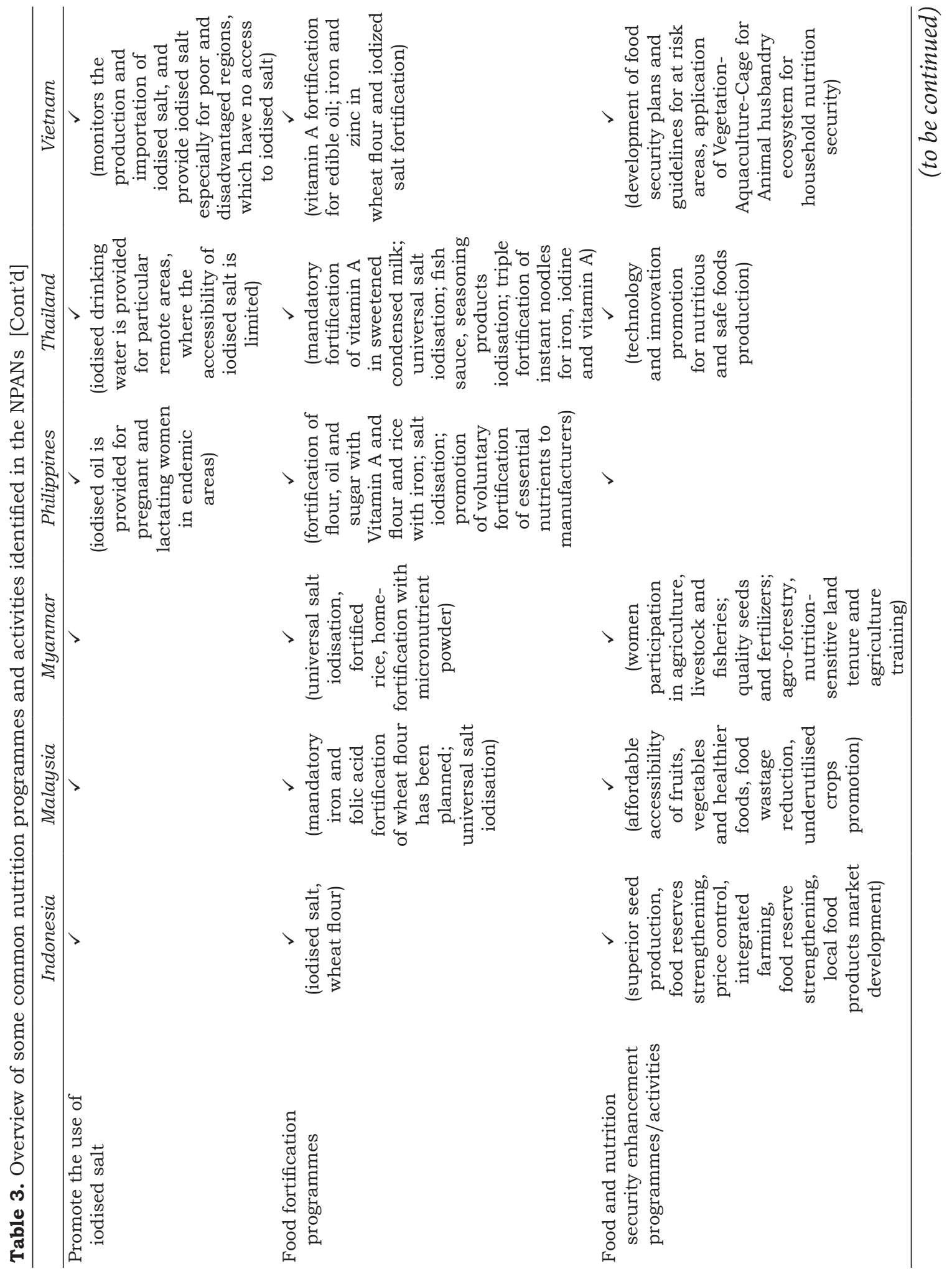




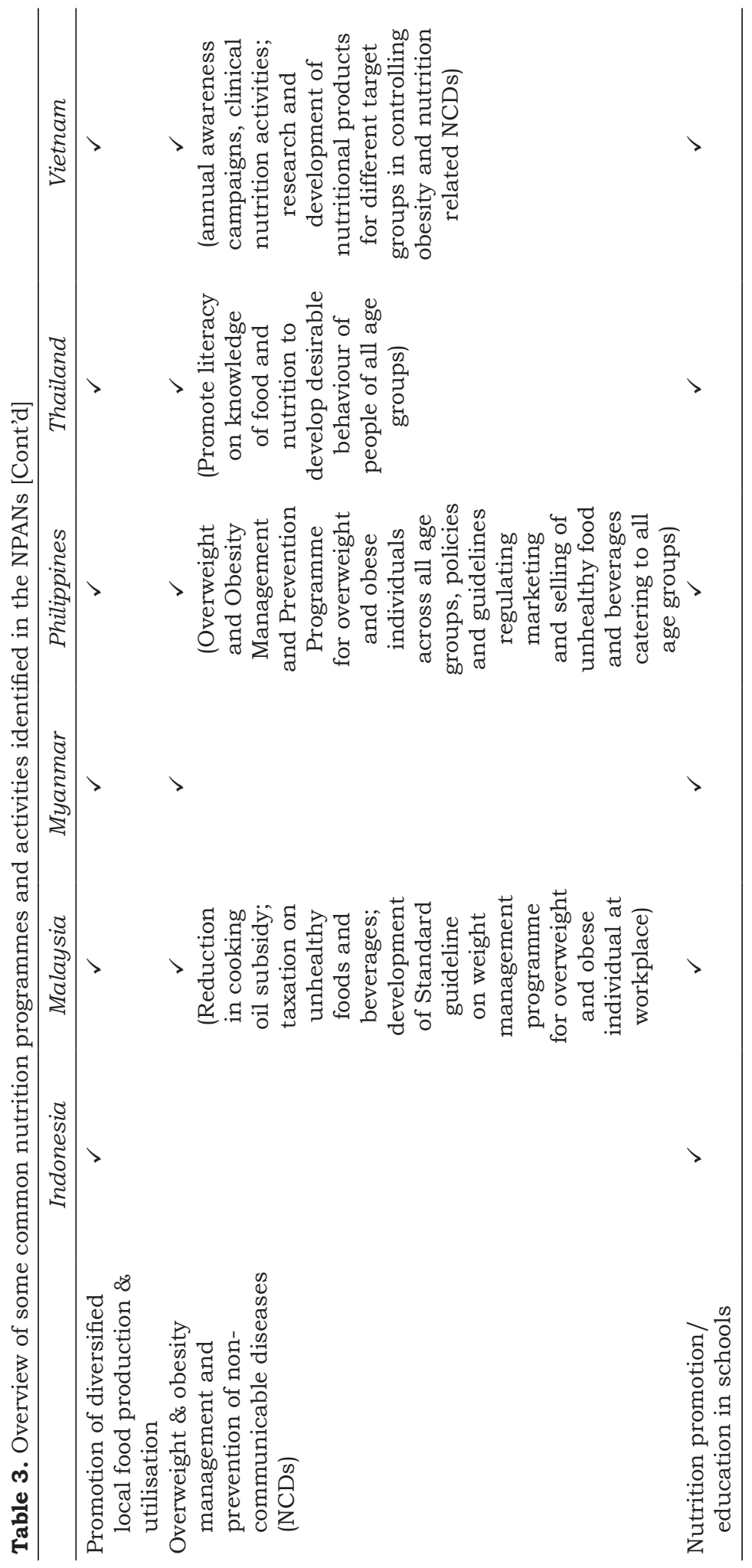


promote the development of technology and innovation for nutritious foods and encourage entrepreneurs and community chefs who have been trained in food production to produce nutritious and safe food products. Other activities identified are as indicated in Table 3.

\section{d. Prevention of non-communicable diseases (NCDs)}

NCDs prevention programmes exist in most countries, mainly focusing on promoting healthy eating and physical activities to prevent overweight and obesity through various approaches and settings (Table 3). Other approaches adopted in Malaysia include taxation of unhealthy foods and beverages.

\section{e. Nutrition promotion \& education in schools}

The importance of schools in nutrition promotion is acknowledged by all NPANs. Healthy eating component is included in the Malaysia's preschool curriculum whereas in Thailand and Vietnam, nutrition education is provided for children from kindergarten through to university. Alongside nutrition education and school feeding, school is used as a platform for the delivery of nutrition-specific interventions to reach school aged children and adolescents who are difficult to access through the health system in Myanmar. In Philippines, nutrition education is delivered through the School Health and Nutrition Programme, integrating school gardening, supplementary feeding and nutrition education. Parent-teacher/ parent teacher associations approach is utilised by most countries (Malaysia, Myanmar and Philippines) to promote nutrition and healthy eating in schools, while some also train the food handlers in schools on healthy meal preparation (Malaysia and Vietnam). Thailand encourages food and nutrition teaching and develop curriculum for both formal and informal education system.

\section{f. Other activities identified}

Other activities identified by the various NPANs include strengthening institutional community capacity for nutrition by improving the number of qualified nutritionists/dietitians in the country; providing training for nutrition, dietetics, and food safety professionals; research and technology development in the areas of nutrition and food.

\section{Performance indicators/outcomes and specific target for indicators}

Target and performance indicators are used by all six countries in monitoring of action plans and programmes. Most of them identified similarindicators that can be categorised into three groups, namely indicators related to nutritional status, food security and micronutrient status (Table 4). Malaysia and Philippines have included the indicators that measure all six global nutrition targets.

Most NPANs do not discuss in detail the process of setting targets for the indicators. It is observed that several global targets and available country's baseline data were used and adopted as point of reference in setting the targets for the performance indicators. For several of the indicators, these countries are in agreement and are aiming collectively to reach the Global Nutrition Targets 2025 and SDGs 2030. All countries except Myanmar aim to achieve no increase from baseline for the childhood overweight rate in the country; increase exclusive breastfeeding rate up to least $50 \%$ (Indonesia), while Malaysia targets exclusive breastfeeding rate up to least $70 \% ; 11-28 \%$ reduction in stunting and reduce childhood wasting to/no more than 5\% (Malaysia, Myanmar, 


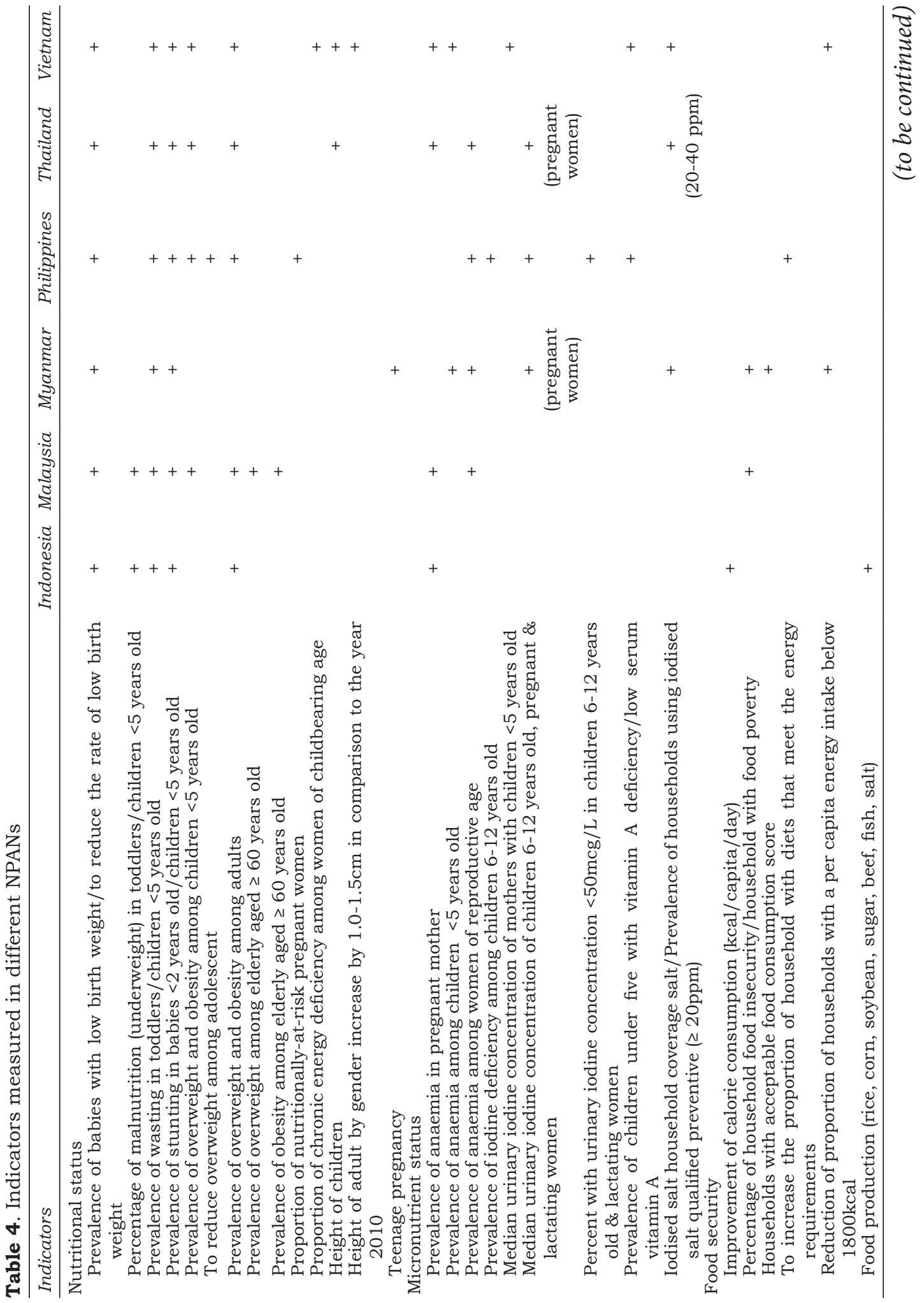


National plans of action for nutrition in SEA countries

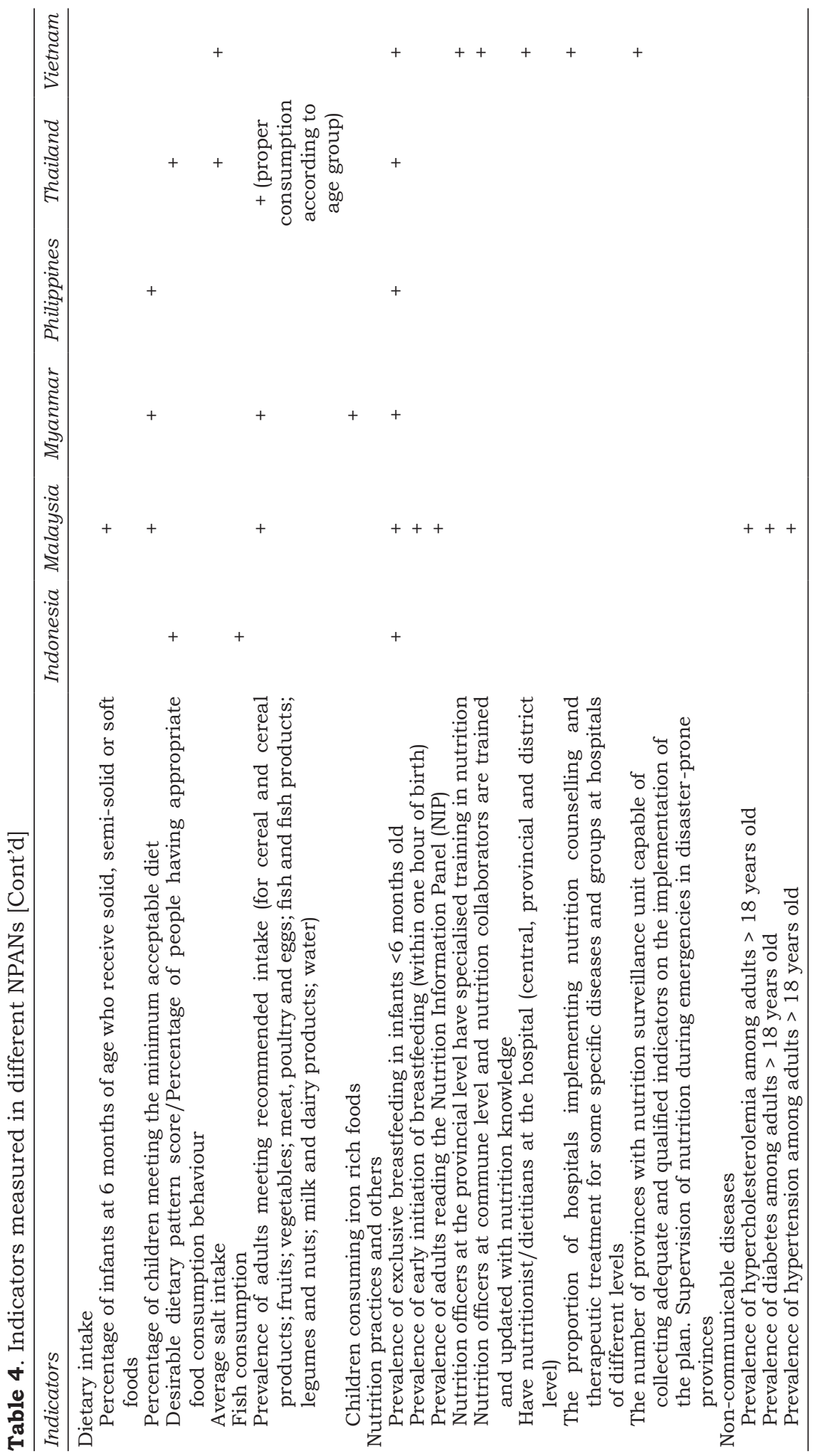


Philippines, Thailand, Vietnam); and 10$30 \%$ reduction in prevalence of low birth weight.

\section{Implementation, management, monitoring \& evaluation}

Implementation \& management

NPANs of the six countries call for multi-sectoral and multi-stakeholder collaboration to ensure more effective implementation of intervention strategies. Decentralisation and multisectoral approach is emphasised by most countries, where the implementation is allocated to a range of different institutions. The implementation is largely led by and coordinated by the Ministry of Health (i.e. Malaysia, Myanmar, Thailand, Vietnam), National Nutrition Council (i.e. Philippines), National Planning Agency or BAPPENAS (Indonesia) or a high level coordinating committee. Some countries such as Indonesia, Myanmar and Philippines develop separate action plans for regional or local level. Specific advisory bodies have been established in most of these countries to provide overall technical assistance and support to all aspects of the action plan. Indonesia, Malaysia and Philippines also established technical working groups to support or facilitate the implementation of the action plan.

\section{Monitoring \& evaluation}

All NPANs in this review underscore the importance of monitoring and evaluation activities. Most of them (Malaysia, Philippines, Indonesia, Vietnam) involve the generation of annual reports on implementation at all levels and progress report from various stakeholders involved. A system of indicators is used by all six countries in monitoring and evaluating the action plan. National health and nutrition surveys (Malaysia, Myanmar, Vietnam, and Philippines), data collection and indicators recorded at all levels (Indonesia, Thailand) form the important part of monitoring and evaluation process of these countries. The national nutrition surveys' findings help the respective countries in evaluating the impact of the strategies, reviewing the priorities and activities of the programme implemented, and plan for future action plan. Most countries also have in place mid-term review and long-term review for the NPANs.

\section{Funding and budget for NPANs}

The action plans of Indonesia, Myanmar, Philippines and Vietnam provide insights into the funding and budget allocation for NPAN implementation.

The primary funding sources for Indonesia, Philippines, Thailand and Vietnam are from the government budget. Other funding for these countries include special funding schemes allocated for certain regional areas and grant donations from corporate sector (Indonesia); funding and investment from development partners / international organisations (Philippines and Vietnam); contribution and mobilisation from the community and domestic organisations (Vietnam). In Vietnam, the largest proportion of the budget is allocated for improving the quantity and quality of people's meals and nutritional status of mothers and children.

Myanmar, Philippines and Vietnam conducted costing analysis for the action plan and estimated the budget required for the action plan activities. Philippines action plan's budget is an estimate of the costs of 38 projects and their ten programmes for the 6-year period whereas Myanmar's action plan provides details on the indicative total cost and funding required to implement and deliver the 5-year sector-level key results. Malaysia NPAN has not provided details of the funds for the implementation of the identified programmes and activities. 


\section{Common challenges in implementing NPANS}

All six NPANs have outlined the key factors that influence the extent to which the planned activities can be implemented successfully. It is not surprising that these countries face some common challenges in implementing the plans.

The need for greater coordination among relevant stakeholders and active community participation are the major challenges facing most countries (Myanmar, Vietnam, Malaysia, Thailand, Indonesia). While the shared responsibility for implementation is emphasised, it appears that the Ministry of Health is often perceived as having sole responsibility on the action plan. Malaysia's NPANM III mentions the need to develop a road map thatallows adequate coordination between national and subnational levels, with involvement of other related stakeholders and community representatives to ensure commitment and active participation. In Indonesia, the lack of public-private partnership, multi-stakeholders coordination in the national and sub-national level have led to low programme coverage for nutrition specific intervention and fragmented nutrition policies and programmes. Vietnam's NPAN also highlights inadequate policy advocacy, attention from the government has caused inadequateness in cross-collaboration and that activities and resources are not being integrated effectively especially at localities. Thailand highlights that the collaboration among agencies and cooperation with private sector needs to be strengthened.

Financial commitment is also a critical factor in NPAN development and implementation (Philippines, Malaysia, Myanmar, Vietnam). In Vietnam, majority of the budget has been allocated to control malnutrition of children under five, and thus insufficient budget for other important nutrition issues. In Philippines, the budget formulation for the current plan has been largely concluded prior to the PPAN formulation exercise. In Malaysia, insufficient political commitment to tackling malnutrition has led to a financial shortfall, posed key challenges in implementing previous NPANM II. Proposal to have a "dedicated" budget (separate from Ministry of Health budget) from the Ministry of Finance to support NPANM activities which are largely prevention in nature, did not materialise.

Lack of human resources capacity or development is another common challenge identified. For example in Malaysia and Thailand, there is insufficient number of nutritionists in the health sector and community-based setting. Thailand highlights that the integration of nutrition professions and networking partners to drive work is a challenge. Vietnam recognises that there is a lack of necessary knowledge and means to propagandise and encourage its people to change their nutritional practices due to the limiting capacity of the nutrition network. Indonesia also highlights that commitment and capacity among sub-national level and the provision of technical support and guidance for districts/regional level needs to be improved.

Several of these countries also face difficulties in efficient monitoring and evaluation of the action plan. Philippines highlights inadequate system for managing the previous action plan and that the past PPANs, including the 2011-2016 plan, were not operational plans, not results-based and posed a challenge in evaluability of the plan. In Malaysia, improvement on timely collection of data for monitoring and evaluation purposes is needed as large national surveys are currently carried out only every few years. Thailand highlights the need for improvement 
of tracking system and evaluations of the projects carried out, as well as the need of incorporating technology use in information management and effective nutritional surveillance.

Indonesia, Vietnam and Myanmar recognise low level of knowledge and awareness on the importance of nutrition among community and local authorities as one of the challenges in implementing their action plans. Thailand recognises that food and nutrition researches conducted in the country are still not meeting the nutritional gaps and needs of the nation. It has also been acknowledged that clearer policies and strategies on food and nutrition of related organisations are needed for promoting nutrition that covers all age groups.

\section{DISCUSSIONS}

Reviewing the NPANs in the six SEA countries, it is recognised that there are more commonalities than differences amongthesecountries. The prioritisations of nutrition interventions outlined are based on respective country context and needs. These country action plans show similarities in several components including objectives, agencies and stakeholders involved, nutritional issues to be addressed, implementation, monitoring and evaluation mechanism as well as challenges in implementing previous NPANs/related documents.

There are, however, differences in a few aspects of the NPANs of these countries, such as the implementation strategies and targets set. Some countries have identified specific nutritional issues and indicators that are considered important to the country context. For example, Indonesia monitors several indicators on food production; Malaysia establishes a few diet-related NCDs indicators; Philippines has specific indicator on the prevalence of nutritionally at-risk pregnant women; Thailand indicators include number of innovations in food production for good nutrition and those related to national food and nutrition database development, whereas Vietnam includes indicators on improvement of population height. In the effort to achieve Global Nutrition Targets 2025, countries have set specific targets that are comparable to Global Nutrition Target especially for the indicators on prevalence of low birth weight (most countries establish target ranging from $22 \%$ to $33 \%$ reduction), childhood overweight (most countries aim to achieve no increase from baseline), and childhood wasting (most countries target a prevalence of no more than $5 \%$ ).

\section{Recommendation/way forward for challenges}

The nutrition situation analysis in the NPANs indicates that most countries in this review have not fully achieved the various nutrition targets set. Several common challenges mentioned earlier (the need for greater coordination among stakeholders, capacity for implementation, monitoring and evaluation system improvement, and significant financial commitment to the NPAN by the government) must be tackled in order to effectively implement the NPAN and achieve the targets.

Clear commitment from various stakeholders is important for the multisectoral coordination mechanism to function effectively. In order to achieve this, various stakeholders in these countries will have to first recognise that the implementation is not the sole responsibility of the health sector and that the responsibility has to be shared across multisectors. However, the various stakeholders involved may have difficulty in visualising common goals as they may hold contradictory opinions and is competing with others for resource allocations to carry out its own mandate. Thus, harmonising their opinions, identifying their needs in earlier phase 
of plan development to ensure that their objectives are not at stake and clearly define the roles and responsibilities for each of the stakeholders are important to ensure good collaboration between them. Activating a nutrition-based mandate across a multiplicity of ministries e.g. using improved nutrition outcomes as one of the performance indicators for relevant stakeholders/ministries could be considered as an approach to improve commitment. For example, Myanmar in its latest MS-NPAN has proposed sector-specific outcomes for different ministries. Besides, population should be actively involved and aware on decision making process, the geographic reach of the programmes should be expanded to reach remote populations, and the community awareness of nutrition problems, programmes and rights should also be improved (Lachat et al., 2005; Gillespie, Bold \& the Stories of Change Study Team, 2017; IFPRI, 2016; WHO, 2006).

The roles of different stakeholders have to be backed up by high quality technical expertise and a serious effort to build capacity. The ability to carry out stated objectives is needed at different levels. Thus it is important to ensure that well-trained personnel and decision makers are employed at different levels to coordinate, implement, monitor and evaluate the programmes and activities implemented. In this context, the establishment of a high quality national nutrition researchand traininginstitution in the country or region that are capable of providing nutrition and continuous professional development training are crucial. Philippines, Thailand and Vietnam have their respective institute of nutrition for research and training namely Institute of Nutrition, Mahidol University (INMU) in Thailand, Food and Nutrition Research Institute (FNRI) in the Philippines, and National Institute of Nutrition in Vietnam. The establishment of National Institute of Nutrition (NIN) is on the implementation agenda of Malaysia NPANM III. Nutrition research, science and technology capacities not only contributes to improving food and nutrition security, but also play crucial roles in providing an evidence base for decisions making and supporting policy making by the authorities/stakeholders. Besides, the adequacy of national technical expertise/capacity need to be assessed (Ismail et al., 2005).

Having a common understanding of the form of capacities needed is crucial before trying to strengthen nutrition capacity especially in low-and middleincome countries (Ismail et al., 2005). Shrimpton et al., (2014) proposed a fourlevel (system, organisational, workforce, community) conceptual framework for capacity development to facilitate a more systematic approach to assessing the need for nutrition capacity development. It is believed that based on such assessment a comprehensive capacity development plan could be established for a country. Myanmar in its latest MSNPAN adopts the methodology and tools recommended by the SUN UN Network Guidelines and Toolkit and exercised a capacity assessment as part of the action plan planning process to review the country's ability to coordinate, implement, and monitor the action plan at different levels.

The execution/implementation of the NPANs will be very much limited when there is lack of data and evidence that are actionable at national and subnational levels. Thus, countries must work on establishing better monitoring and evaluation systems to ensure that timely, nationally representative data/ information on outcomes of actions and trends of nutritional issues are available and accessible to evaluate and advise plan/programme development. National nutrition surveys or nutrition surveillance should be conducted in a 
periodic manner covering all priority nutrition indicators. New surveillance systems in areas still not covered should also be developed. Effective evaluations include not only the assessments of whether a plan works but also the process evaluations that highlight impact pathways in order to better understand why, how, and where programme/ plan work, or do not work (Gillespie, Bold \& the Stories of Change Study Team, 2017). Besides, monitoring and evaluation should also include the timely management, analysis interpretation, dissemination and communication of accurate nutrition data to and among relevant stakeholders. Countries in the SEA region should take heed of these important aspects and work towards acquiring quality food and nutrition data.

To better support financial commitment, countries may need to consider costing their nutrition plans and exercising budget analyses. Costing help to estimate the funding needed to implement nutrition activities and it serves as a first step in understanding overall resources required to support nutrition actions in a country (SPRING, 2018). With this, it helps policy makers to prioritise among the different implementation strategies in order that the funding can be allocated properly. Besides, it would be helpful to develop appropriate analyses and evidence through budget and expenditure analyses to demonstrate how much money can be lost to poor nutrition of the population if national resources are not invested appropriately in nutrition policy/programmes implementation. This could help to make a powerful case to target decision makers e.g. Ministry of Finance who have the power over budgets and spending for increased funding for nutrition.

\section{CONCLUSION}

The development of food and nutrition action plans by governments is vital in providing practical guidance to significantly reduce the burden of preventable diet-related NCDs and all other forms of malnutrition prevalent in the country. All six SEA countries in this review have recognised this importance and have respectively formulated their NPANs to provide a framework for coordinated implementation of nutrition intervention activities by the government and food and nutrition related stakeholders. It is imperative that there must be effective implementation, monitoring and evaluation of the plans so as to successfully address both extremes of the challenging nutrition situation in SEA countries. However, based on the various challenges highlighted by the countries in the implementation of these action plans, it is clear that a great deal remains to be done to be able to achieve the planned targets. The similarities in the nutritional issues, challenges for implementation, multi-sectoral implementation mechanism as well as the programmes/activities identified suggest that closer collaboration among countries on NPANs, periodic exchange of experiences among countries in the development and implementation of NPANs, and discussion on specific topics in NPAN will benefits the countries in the region.

\section{Acknowledgement}

This work was conducted by the Southeast Asia Public Health Nutrition Network. The authors acknowledge the financial support of BENEOInstitute, DuPont Nutrition \& Biosciences and PepsiCo Services Asia Ltd to enable this work to be carried out.

\section{Authors' contribution}

All authors contributed to the preparation of the paper and approved the final draft of the manuscript. 


\section{Conflict of interest}

The authors declare that they have no conflicts of interest.

\section{References}

BAPPENAS Indonesia (2015). National Food and Nutrition Action Plan Indonesia (Rencana Aksi Nasional Pangan Dan Gizi Tahun) 2015-2019. Ministry of National Development Planning/ National Development Planning Agency (Kementerian Perencanaan Pembangunan Nasional/Badan Perencanaan Pembangunan Nasional). From https://www.scribd.com/ document/318524987 / Dokumen-RAN-PG2015-2019-edit12April-doc [Retrieved 12 February 2018]

Gillespie S, Bold M van den \& the Stories of Change Study Team (2017). Stories of Change in nutrition: An overview. Global Food Security 13: 1-11. From https://doi.org/10.1016/j. gfs.2017.02.004 [Retrieved 1 July 2018]

IFPRI (2016). Taking action: Progress and challenges in implementing nutrition policies and programs. In Global Nutrition Report 2016: From Promise to Impact: Ending Malnutrition by 2030. Chapter 5. Pp. 44-59. Washington, D.C.

International Food Policy Research Institute (IFPRI). From http://dx.doi. org/10.2499/9780896295841_05] [Retrieved 30 June 2018]

Ismail S, Immink M \& Nantel G (2005). Improving Nutrition Programmes An Assessment Tool for Action. Revised Edition. Food and Nutrition Division. Food and Agriculture Organization of the United Nations. Rome. From http://www. fao.org/docrep/009/a0244e/a0244e00.htm [Retrieved 30 June 2018]

Lachat C, Van Camp J, De Henauw S, Matthys C, Larondelle Y, Remaut-De Winter AM \& Kolsteren P. (2005). A concise overview of national nutrition action plans in the European Union Member States. Public Health Nutr. 8(3):266-74. From https://doi.org/10.1079/ PHN2004691 [Retrieved 1 May 2018] \

MOPH Thailand (2019). The 5-Year National Plan of Action for Nutrition 2019-2023. Bureau of Nutrition, Department of Health, Ministry of Health Thailand.

NCCFN Malaysia (2016). National Plan of Action for Nutrition of Malaysia III 2016-2025. National Coordinating Committee on Food and Nutrition, Ministry of Health Malaysia, Putrajaya.
MOH Vietnam (2018). National Plan of Action for Nutrition to 2020. Ministry of Health Vietnam, Hanoi, Vietnam.

NNC Myanmar (2018). Multi-Sectoral National Plan of Action on Nutrition (MS-NPAN) 2018/19-2022/23. National Nutrition Centre, Department of Public Health, Ministry of Health and Sports, the Republic of the Union of Myanmar. From https://www.mohs.gov.mm/ page/7190 [Retrieved 29 July 2020]

NNC Philippines (2017). Philippine Plan of Action for Nutrition 2017-2022 A Call to Urgent Action for Filipinos and Its Leadership Executive Summary. National Nutrition Council, Department of Health, Manila, Philippines. From http:// www.nnc.gov.ph/index.php/downloads / category/118-ppan.html [Retrieved 7 October 2018]

Shrimpton R, Hughes R, Recine E, Mason JB, Sanders D, Marks GC \& Margetts B (2014). Nutrition capacity development: a practice framework. Public Health Nutr.17(3):6828. From https://doi.org/10.1017/ S1368980013001213 [Retrieved 1 July 2018]

Shrimpton \& Rokx (2012). The double burden of malnutrition: a review of global evidence (English). Health, Nutrition and Population (HNP) discussion paper. Washington D.C. World Bank. From http://documents.worldbank. org/curated/en/905651468339879888/Thedouble-burden-of-malnutrition-a-review-ofglobal-evidence [Retrieved 2 May 2018]

SPRING (2018). Putting Budget Data to Work for Nutrition. Arlington, VA: Strengthening Partnerships, Results, and Innovations in Nutrition Globally (SPRING) project. From https://www.springnutrition.org/sites / default/files/ publications/briefs/budget_ data_nutrition_brief.pdf [Retrieved 1 July 2018]

Tee ES, Hardinsyah R, Ismail MN, May KT, Florentino RF, Saipin C \& Hop LT (2018). National Plans of Action for Nutrition in Southeast Asian Countries - A Review. Southeast Asia Public Health Nutrition Network. c/o Nutrition Society of Malaysia, Kuala Lumpur.

WHO (2000). Development of the first food and nutrition action plan for the WHO European Region. Report on a WHO Consultation. World Health Organization, Regional Office for Europe, Copenhagen. From http://apps.who.int/iris/ bitstream/handle/10665/ 108297 / E68895. pdf; jessionid=01E301 FEOBD39EB72FBBC 17E96B168E5?sequence $=1$ [Retrieved 6 May 2018] 
WHO (2006). Comparative analysis of nutrition policies in the WHO European Region. A comparative analysis of nutrition policies and plans of action in WHO European. World Health Organization, Regional Office for Europe, Copenhagen. From http://www.euro.who. int/__data/assets / pdf_file/0004/149782/ instanbul_conf_20ebd02.pdf [Retrieved 22 April 2018)
WHO (2016). Strategic Action Plan to reduce the double burden of malnutrition in the SouthEast Asia Region 2016-2025. World Health Organization. Regional Office for South-East Asia, India. From http://apps.searo.who.int/ PDS_DOCS/B5295.pdf [Retrieved 8 May 2018] 